\title{
In-situ Infrared Study of the Adsorption and Surface Acid-Base Properties of the Anions of Dicarboxylic Acids at Gold Single Crystal and Thin-Film Electrodes.
}

José Manuel Delgado, Antonio Berná, José Manuel Orts, Antonio Rodes* and Juan Miguel Feliu

Supporting information

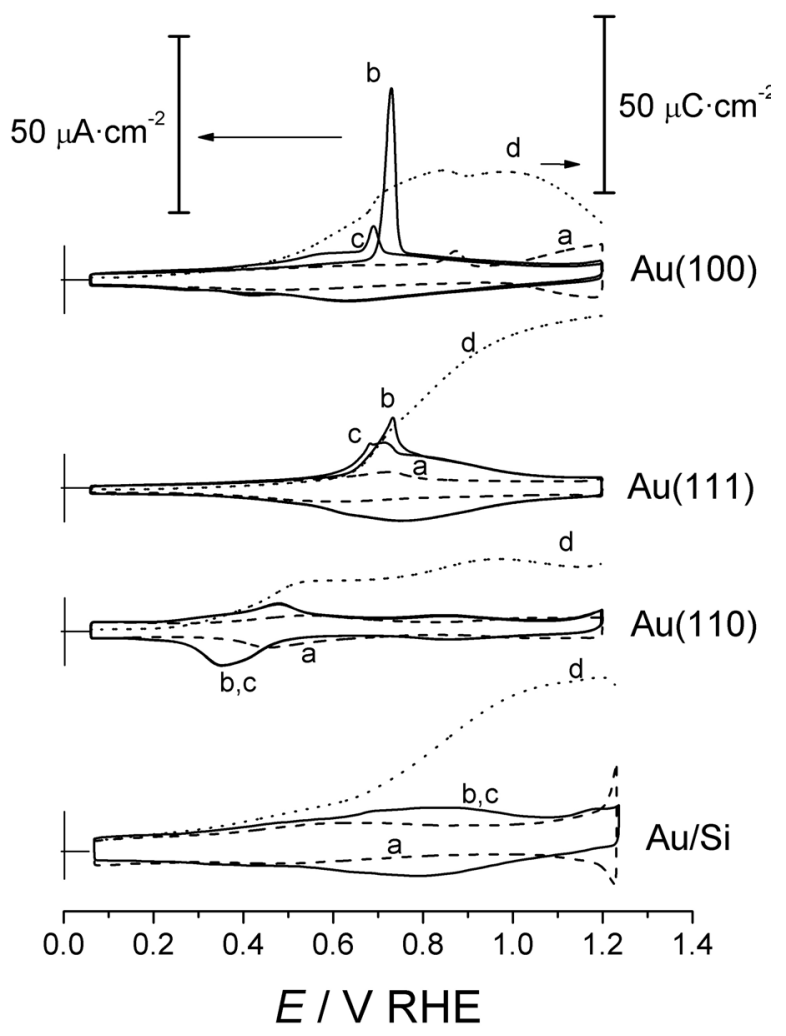

Cyclic voltammograms for $\mathrm{Au}(100), \mathrm{Au}(111), \mathrm{Au}(110)$ and an electrochemically annealed thin-film gold electrode in $0.1 \mathrm{M} \mathrm{HClO}_{4}$ (a, dashed line) and $0.01 \mathrm{M} \mathrm{H}_{4} \mathrm{C}_{3} \mathrm{O}_{4}+$ $0.1 \mathrm{M} \mathrm{HClO}_{4}$ (b and c, solid lines, correspond to the first and second voltammetric cycle, respectively). Sweep rate: $50 \mathrm{mV} \mathrm{s}^{-1}$. Dotted curves (d) correspond to the charge density vs potential curves calculated by integrating the difference between voltammetric curves $\mathrm{c}$ and $\mathrm{a}$. 


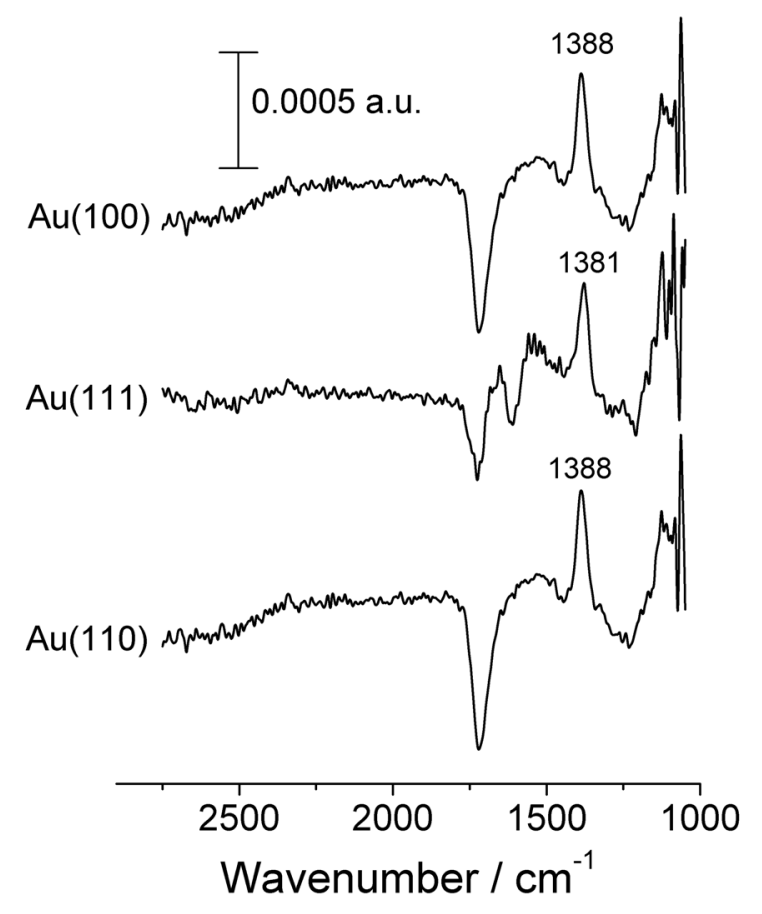

Potential-difference spectra collected at $1.20 \mathrm{~V}$ for a $\mathrm{Au}(100), \mathrm{Au}(111)$ and $\mathrm{Au}(110)$ electrodes in $0.01 \mathrm{M} \mathrm{H}_{4} \mathrm{C}_{3} \mathrm{O}_{4}+0.1 \mathrm{M} \mathrm{HClO}_{4}$ solutions. Reference potential: $0.10 \mathrm{~V}$; 1000 interferograms collected at each potential. 


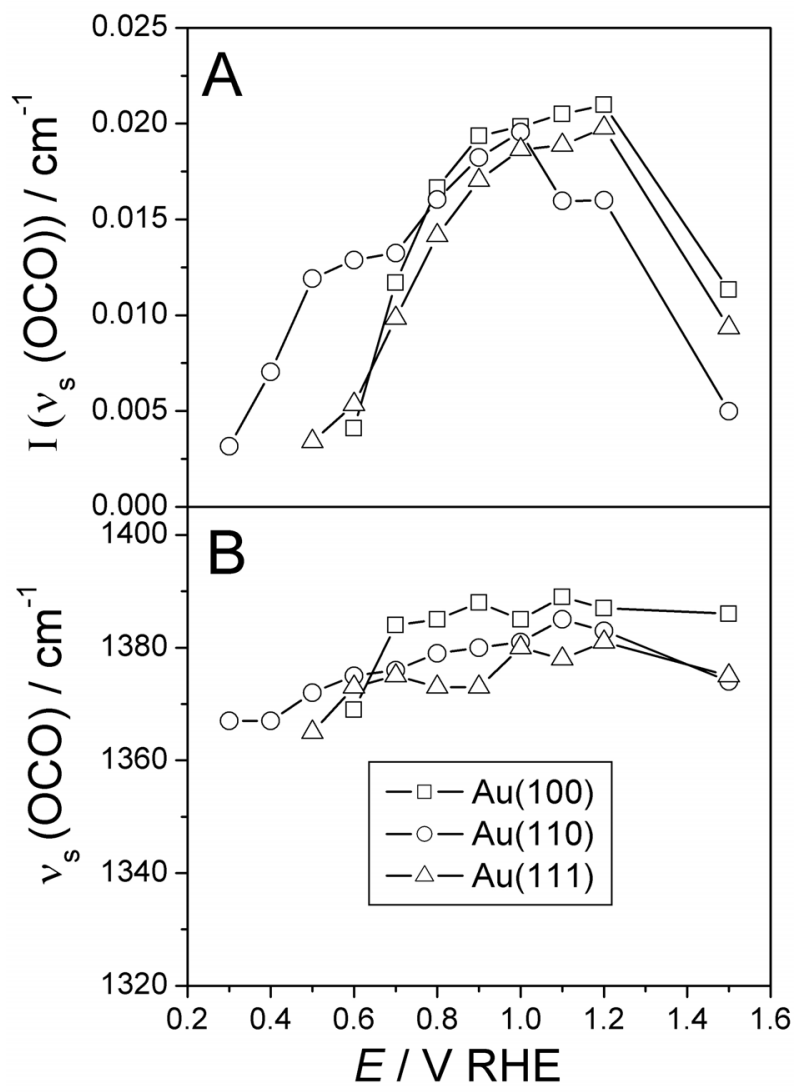

Plots of (A) the integrated intensity and (B) the adsorbate band frequencies of the adsorbate bands as measured in the potential-difference spectra collected for $\mathrm{Au}(100)$, $\mathrm{Au}(111)$ and $\mathrm{Au}(110)$ electrodes in contact with $0.01 \mathrm{M} \mathrm{H}_{4} \mathrm{C}_{3} \mathrm{O}_{4}+0.1 \mathrm{M} \mathrm{HClO}_{4}$ solutions. 


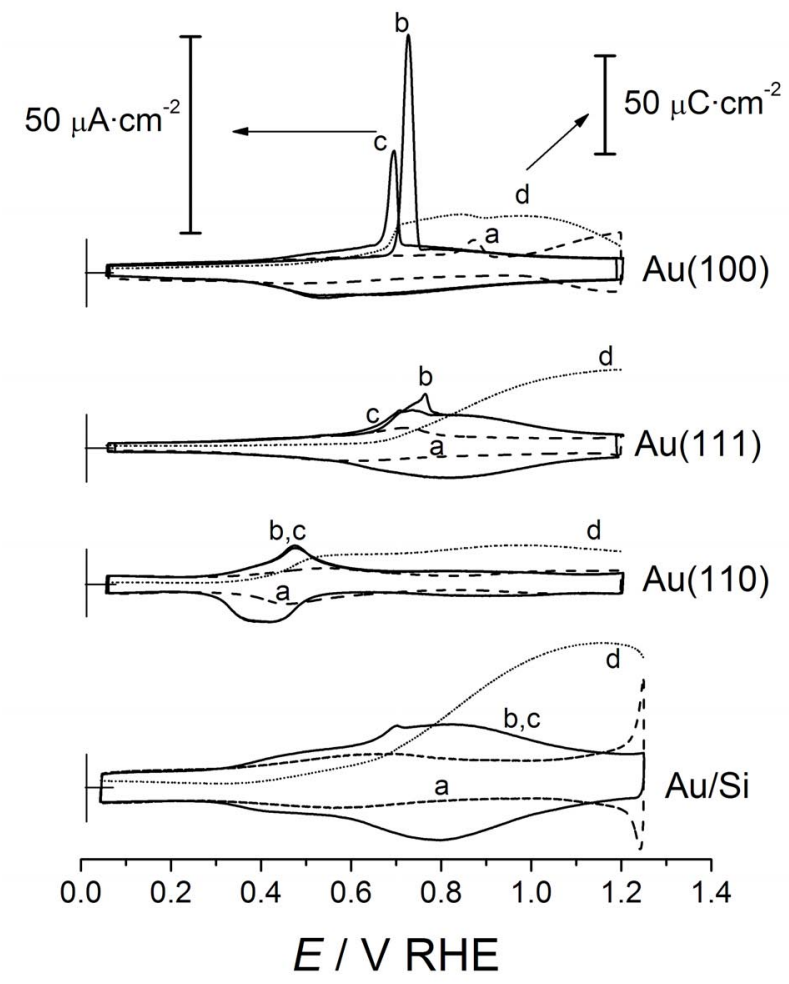

Cyclic voltammograms for $\mathrm{Au}(100), \mathrm{Au}(111), \mathrm{Au}(110)$ and an electrochemically annealed thin-film gold electrode in $0.1 \mathrm{M} \mathrm{HClO}_{4}$ (a, dashed line) and $0.01 \mathrm{M} \mathrm{H}_{6} \mathrm{C}_{4} \mathrm{O}_{4}+$ $0.1 \mathrm{M} \mathrm{HClO}_{4}$ (b and c, solid lines, correspond to the first and second voltammetric cycle, respectively). Sweep rate: $50 \mathrm{mV} \mathrm{s}^{-1}$. Dotted curves (d) correspond to the charge density vs potential curves calculated by integrating the difference between voltammetric curves $\mathrm{c}$ and $\mathrm{a}$. 


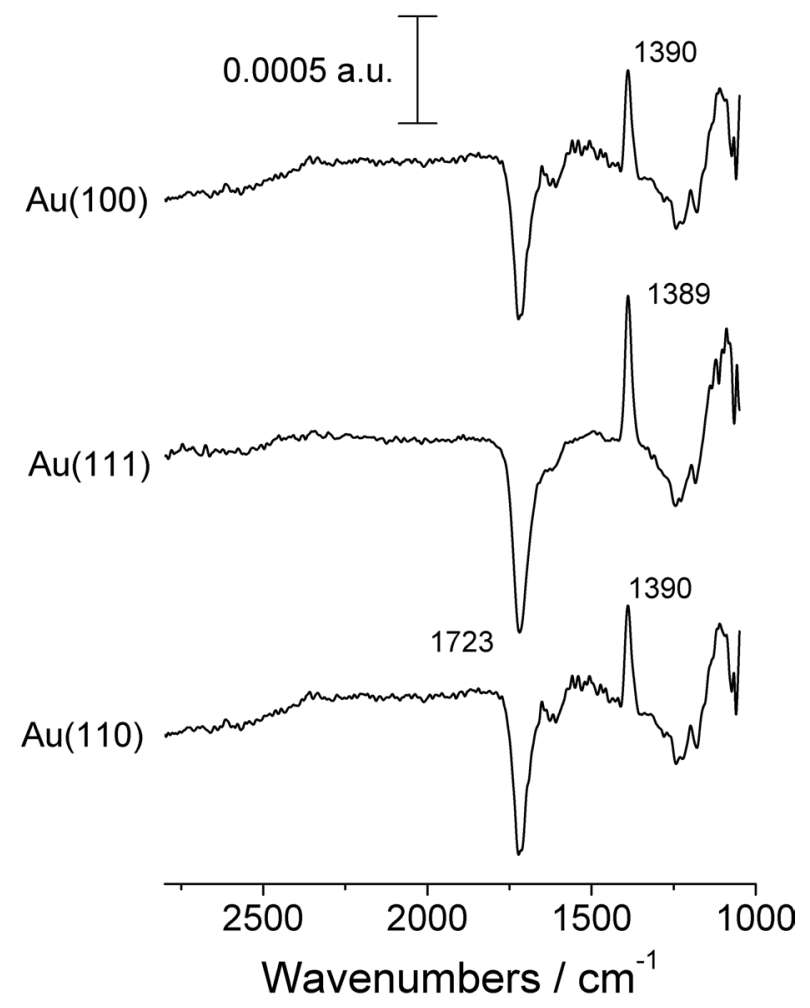

Potential-difference spectra collected at $1.20 \mathrm{~V}$ for a $\mathrm{Au}(100), \mathrm{Au}(111)$ and $\mathrm{Au}(110)$ electrodes in $0.01 \mathrm{M} \mathrm{H}_{6} \mathrm{C}_{4} \mathrm{O}_{4}+0.1 \mathrm{M} \mathrm{HClO}_{4}$ solutions. Reference potential: $0.10 \mathrm{~V}$; 1000 interferograms collected at each potential. 